\title{
Brain oxidative stress in a triple-transgenic mouse model of Alzheimer disease
}

\author{
Rosa Resende ${ }^{a, b}$, Paula Isabel Moreira ${ }^{b, c}$, Teresa Proença ${ }^{d}$, Atul Deshpande ${ }^{\mathrm{e}}$, Jorge Busciglio ${ }^{\mathrm{e}}$, \\ Cláudia Pereira $^{\mathrm{a}, \mathrm{b}, *}$, Catarina Resende Oliveira ${ }^{\mathrm{a}, \mathrm{b}}$ \\ a Institute of Biochemistry, Faculty of Medicine, University of Coimbra, 3004-504 Coimbra, Portugal \\ b Center for Neuroscience and Cell Biology, University of Coimbra, 3004-504 Coimbra, Portugal \\ c Institute of Physiology, Faculty of Medicine, University of Coimbra, 3004-504 Coimbra, Portugal \\ d Department of Neurology, Coimbra University Hospitals, University of Coimbra, 3004-504 Coimbra, Portugal \\ e Department of Neurobiology and Behavior, University of California at Irvine, Irvine, CA 92697, USA
}

\section{A R T I C L E I N F O}

\section{Article history:}

Received 8 December 2007

Revised 29 February 2008

Accepted 18 March 2008

Available online 28 March 2008

\section{Keywords:}

Alzheimer disease

$3 \times \operatorname{Tg}-\mathrm{AD}$ mouse

Oxidative stress

Lipid peroxidation

Antioxidants

Free radicals

\begin{abstract}
A B S T R A C T
Alzheimer disease (AD) is a neurodegenerative disease which is characterized by the presence of extracellular senile plaques mainly composed of amyloid- $\beta$ peptide $(A \beta)$, intracellular neurofibrillary tangles, and selective synaptic and neuronal loss. AD brains revealed elevated levels of oxidative stress markers which have been implicated in $A \beta$-induced toxicity. In the present work we addressed the hypothesis that oxidative stress occurs early in the development of $\mathrm{AD}$ and evaluated the extension of the oxidative stress and the levels of antioxidants in an in vivo model of $\mathrm{AD}$, the triple-transgenic mouse, which develops plaques, tangles, and cognitive impairments and thus mimics AD progression in humans. We have shown that in this model, levels of antioxidants, namely, reduced glutathione and vitamin E, are decreased and the extent of lipid peroxidation is increased. We have also observed increased activity of the antioxidant enzymes glutathione peroxidase and superoxide dismutase. These alterations are evident during the $A \beta$ oligomerization period, before the appearance of $A \beta$ plaques and neurofibrillary tangles, supporting the view that oxidative stress occurs early in the development of the disease.
\end{abstract}

(C) 2008 Elsevier Inc. All rights reserved.
Alzheimer disease (AD) is a neurodegenerative disease characterized by the presence of senile plaques mainly composed of fibrillar amyloid- $\beta$ peptide (A $\beta$ ) [1] and neurofibrillary tangles (NFTs) composed of paired helical filaments (PHF) of hyperphosphorylated tau $[2,3]$. Plaques and tangles are present mainly in brain regions involved in learning and memory such as cortex and hippocampus. These affected regions typically exhibit synaptic and neuronal loss, with cholinergic and glutamatergic neurons being the most affected [4].

Whereas the majority of AD patients suffer from the sporadic form of the disease, there is an inherited familial form caused by rare mutations in the APP or PS1 gene [5]. However, the neuropathological features are shared by both sporadic and familiar forms. $A \beta$ can

Abbreviations: AD, Alzheimer disease; $A \beta$, amyloid- $\beta$ peptide; $t$-BHP, tert-butylhydroperoxide; GPX, glutathione peroxidase; GRd, glutathione redutase; GSH, reduced glutathione; GSSG, oxidized glutathione; HPLC, high-performance liquid chromatography; MDA, malondialdehyde; NBT, nitroblue tetrazolium; NFT, neurofibrillary tangle; OPT, ortho-phetaldialdehyde; PHF, paired helical filament; SOD, superoxide dismutase; $3 \times \mathrm{Tg}-\mathrm{AD}$, triple-transgenic model of Alzheimer disease; TBA, thiobarbituric acid; TBARS, thiobarbituric acid-reactive substances.

* Corresponding author. Institute of Biochemistry, Faculty of Medicine, University of Coimbra, 3004-504 Coimbra, Portugal. Fax: +351 239822776.

E-mail address: cpereira@cnc.cj.uc.pt (C. Pereira). accumulate through overproduction or decreased clearance, leading to neurotoxicity and cell death. Although the mechanisms through which $A \beta$ exerts its toxicity remain unclear, it seems that oxidative stress plays an important role [6,7]. $A \beta$ and oxidative stress are linked to each other because $A \beta$ produces oxidative stress [8-11], and prooxidants, in turn, increase $A \beta$ production [12,13]. Moreover, several antioxidants, namely vitamin $\mathrm{E}$ and melatonin, were shown to protect neurons from $A \beta$-induced toxicity [8-11]. $A \beta$-mediated oxidative stress can be due to either an increase in reactive oxygen species (ROS) production or a decrease in the endogenous antioxidants, namely, in the activity of antioxidant enzymes such as superoxide dismutase (SOD) and glutathione peroxidase (GPx) and of nonenzymatic antioxidants such as vitamin E and GSH [14]. Elevated levels of oxidative stress markers, namely protein carbonyls, thiobarbituric acid-reactive substances (TBARS), 4-hydroxy-2-trans-nonenal (HNE), 8-hydroxy-2deoxyguanine (8-OHdG), and 8-hydroxyguanine (8-OHG), have been found in AD brains $[15,16]$ and it has been suggested that oxidative stress is an early event that contributes to AD pathology before the appearance of amyloid plaques [17,18].

Recently, Oddo and colleagues developed a new AD mouse model that harbors PS1 ${ }_{\text {M146 v }}$, APP $_{\text {Swe }}$, and tau $u_{\text {P301L }}$ mutations [19] and that progressively develops extracellular senile plaques, intracellular NFTs, and cognitive impairments [19-21]. Furthermore, this model is crucial to study the relationship between $A \beta$ and tau pathologies. In fact, it 
has been demonstrated that genetically augmenting tau levels and hyperphosphorylation in the $3 \times \mathrm{Tg}-\mathrm{AD}$ mouse has no effect on the onset and progression of $A \beta$ pathology, suggesting that the link between $A \beta$ and tau is predominantly if not exclusively unidirectional [22]. Moreover, $A \beta$ immunotherapy reduces soluble tau and ameliorates behavioral deficits in old transgenic mice $[23,24]$. In addition, Billings and colleagues [25] have demonstrated that spatial training reduces $A \beta$ and tau pathologies and amielorates the spatial memory decline.

Given the critical role that oxidative stress plays in the pathogenesis of $\mathrm{AD}$, the present work was aimed at evaluating the extension of oxidative stress and the levels of antioxidant defenses in the 3×Tg-AD mouse that closely mimics AD progression in humans [19,20]. We have observed increased levels of oxidative stress, in particular, enhanced lipid peroxidation and decreased levels/activity of both enzymatic and nonenzymatic antioxidants, in these transgenic mice before the appearance of $A \beta$ plaques and neurofibrillary tangles, supporting the view that oxidative stress occurs early in the development of the disease.

\section{Experimental procedures}

\section{Materials}

Reduced (GSH) and oxidized glutathione (GSSG), nitroblue tetrazolium (NBT), GPX and glutathione reductase (GRd), SOD, xanthine oxidase, hypoxanthine, ortho-phetaldialdehyde (OPT), N-ethylmaleimide (NEM), $\beta$-nicotinamide adenine dinucleotide phosphate reduced form ( $\beta$-NADPH), and tert-butylhydroperoxide ( $t$-BHP) were obtained from Sigma Chemical Co. (St. Louis, MO, USA). The Oxiselect HNE-His Adduct ELISA Kit was purchased from Cell Biolabs (San Diego, CA, USA). All the other chemicals were obtained from Sigma Chemical Co. or from Merck kgaA (Damstadt, Germany).

\section{Transgenic mice and brain homogenate preparation}

The derivation and characterization of triple-transgenic $(3 \times \mathrm{Tg}-\mathrm{AD})$ mice have been described previously $[19,20]$. Briefly, human APP cDNA harboring the Swedish mutation (KM670/671NL) and human fourrepeat tau harboring the P301L mutation were comicroinjected into single-cell embryos of homozygous PS1 M146v knock-in mice. The PS1 mice were originally generated on a hybrid 129/C57BL6 background [26]. Age-and gender-matched nontransgenic and PS1 knock-in mice were used as controls. Non-Tg, PS1, and $3 \times \mathrm{Tg}-\mathrm{AD}$ mice were obtained from Dr. Frank LaFerla's laboratory at the Department of Neurobiology and Behaviour and Institute for Brain Aging and Dementia, University of California at Irvine. Brain cortices isolated from 3-to 5-month-old females were frozen and stored at $-80^{\circ} \mathrm{C}$ before being homogenized in $0.32 \mathrm{M}$ sucrose, $1 \mathrm{mM}$ EDTA, $10 \mathrm{mM}$ Tris, pH 7.4. Protein content of brain homogenates was determined by using the Bio-Rad protein dye assay reagent.

\section{Measurement of lipid peroxidation}

The extent of lipid peroxidation in brain homogenates was determined by measuring TBARS and malondialdehyde (MDA). TBARS levels were quantified using the TBA assay [27]. Brain homogenates were diluted two times with 15\% trichloroacetic acid, $0.375 \%$ TBA, $0.25 \mathrm{M}$ $\mathrm{HCl}$, and $0.015 \%$ 2,6-di-tert-butyl-4-methylphenol and boiled for $15 \mathrm{~min}$. The samples were chilled on ice and centrifuged for $10 \mathrm{~min}$ at $95.5 \mathrm{~g}$ in an Eppendorf 5810R centrifuge. The absorbance of the collected supernatants was then measured at $530 \mathrm{~nm}$ using a microplate reader (Spectra Max Plus 384; Molecular Devices). The amount of TBARS formed was calculated using a molar extinction coefficient of $1.56 \times 10^{5} \mathrm{M}^{-1} \mathrm{~cm}^{-1}$ and expressed as nanomoles TBARS produced per milligram of protein. The MDA levels were determined by highperformance liquid chromatography (HPLC) [28], using a Gilson HPLC apparatus with a reverse-phase column (RP18 Spherisorb, S5 OD2). The samples were eluted at a flow rate of $1 \mathrm{ml} / \mathrm{min}$ and detection was performed at $532 \mathrm{~nm}$. The MDA content was calculated from a standard curve prepared using the thiobarbituric acid-MDA complex and was expressed as nanomoles per milligram of protein. As a measure of lipid peroxidation, the levels of hydroxynonenal-histidine (HNE-His) protein adducts were also quantified by using the Oxiselect HNE-His Adduct ELISA Kit (Cell Biolabs, Inc.). The quantity of HNE-His protein adduct in brain homogenates was determined using a standard curve containing known amounts of HNE-BSA $(0-10 \mu \mathrm{g} / \mathrm{ml})$.

\section{Measurement of superoxide dismutase activity}

The activity of SOD was evaluated using a spectrophotometric assay described by Flohé and Ötting [29]. After $2 \mathrm{~min}$ incubation of $100 \mu \mathrm{g}$ of protein in $1.4 \mathrm{ml}$ of phosphate buffer $\left(50 \mathrm{mM} \mathrm{K}_{2} \mathrm{HPO}_{4}\right.$ and $100 \mu \mathrm{M}$ EDTA, pH 7.8) containing $200 \mu 10.025$ mM hypoxanthine, $66.7 \mu l$ Triton $\mathrm{X}-100$, and $66.7 \mu \mathrm{l} 0.1 \mathrm{mM} \mathrm{NBT}$, the reaction was initiated by the addition of $2 \mu \mathrm{l} 0.025 \mathrm{U} / \mathrm{ml}$ xanthine oxidase. The reduction of NBT was measured at $550 \mathrm{~nm}$ (V560 UV/Vis spectrophotometer) for $3 \mathrm{~min}$, at $25^{\circ} \mathrm{C}$ against a blank prepared in the absence of hypoxanthine. The activity of SOD was calculated using a standard curve containing known amounts of SOD (0.25-2 U).

\section{Measurement of glutathione peroxidase and glutathione reductase activities}

GPx and GRd activities were determined spectrophotometrically at $340 \mathrm{~nm}$ by the analysis of NADPH oxidation [30,31]. The activity of GPX was measured after a 5-min incubation, in the dark, of $10 \mu \mathrm{l}$ of each sample with $100 \mu \mathrm{l}$ phosphate buffer $\left(0.25 \mathrm{M} \mathrm{KH}_{2} \mathrm{PO}_{4}, 0.25 \mathrm{M} \mathrm{K}_{2} \mathrm{HPO}_{4}\right.$, $0.5 \mathrm{mM}$ EDTA, pH 7.0), $100 \mu \mathrm{l} 10 \mathrm{mM} \mathrm{GSH}, 100 \mu \mathrm{l} 1 \mathrm{unit}$ GRd, and $480 \mu \mathrm{l}$ $\mathrm{H}_{2} \mathrm{O}$. Then, $100 \mu \mathrm{l} 2.5 \mathrm{mM}$ NADPH and $100 \mu \mathrm{l} 12 \mathrm{mM} t$-BHP were added and the absorbance was measured at $340 \mathrm{~nm}$ (Jasco V560 UV/Vis spectrophotometer) for $5 \mathrm{~min}$, with continuous stirring, against blanks prepared in the absence of NADPH.

For the determination of the activity of the GRd, $200 \mu$ l of each sample was incubated for $30 \mathrm{~s}$ with $1 \mathrm{ml}$ phosphate buffer $(0.2 \mathrm{M}$ $\mathrm{KH}_{2} \mathrm{PO}_{4}, 2$ mM EDTA, pH 7.0), $100 \mu \mathrm{l} 2 \mathrm{mM}$ NADPH, and $700 \mu \mathrm{H}_{2} \mathrm{O}$. The reaction was initiated by the addition of $20 \mathrm{mM}$ GSSG. After $3 \mathrm{~min}$ at $30^{\circ} \mathrm{C}$ with continuous stirring, the absorbance was measured at $340 \mathrm{~nm}$ (Jasco V560 UV/Vis spectrophotometer), against blanks in the absence of GSSG. Results were normalized for the amount of protein per sample.

\section{Measurement of glutathione content}

Brain levels of reduced and oxidized glutathione were measured using a fluorimetric assay, according to Hissin and Hilf [32]. Briefly, $1 \mathrm{mg}$ of protein from the brain homogenates was rapidly centrifuged at $100,000 \mathrm{~g}$ (Beckman, TL-100 ultracentrifuge) for 30 min with $1.5 \mathrm{ml}$ phosphate buffer ( $100 \mathrm{mM} \mathrm{NaH}_{2} \mathrm{PO}_{4}, 5 \mathrm{mM}$ EDTA, pH 8.0) and $0.5 \mathrm{ml}$ $2.5 \% \mathrm{H}_{3} \mathrm{PO}_{4}(\mathrm{v} / \mathrm{v})$. GSH levels were measured after the addition of $100 \mu \mathrm{l}$ of OPT $(1 \mathrm{mg} / \mathrm{ml}$ in methanol) to $100 \mu \mathrm{l}$ of the sample supernatant and $1.8 \mathrm{ml}$ phosphate buffer and incubation at room temperature for $15 \mathrm{~min}$. For GSSG determination, $250 \mu \mathrm{l}$ of the supernatant was added to $100 \mu \mathrm{l}$ of NEM $(5 \mathrm{mg} / \mathrm{ml}$ in methanol) and incubated at room temperature for $30 \mathrm{~min}$. Then, $140 \mu \mathrm{l}$ of this mixture was incubated for $15 \mathrm{~min}$ with $100 \mu \mathrm{l}$ OPT in $1.76 \mathrm{ml} \mathrm{NaOH}(100 \mathrm{mM})$. Finally, the fluorescence was measured at 420-and 350-nm emission and excitation wavelengths, respectively. The measurements were performed in a Perkin-Elmer Luminescence Spectrometer LS 50B. The GSH and GSSG levels were determined by comparison with linear standard curves containing known concentrations of GSH or GSSG $(0-1 \mu \mathrm{g})$ and results were normalized for the amount of protein per sample. 
A
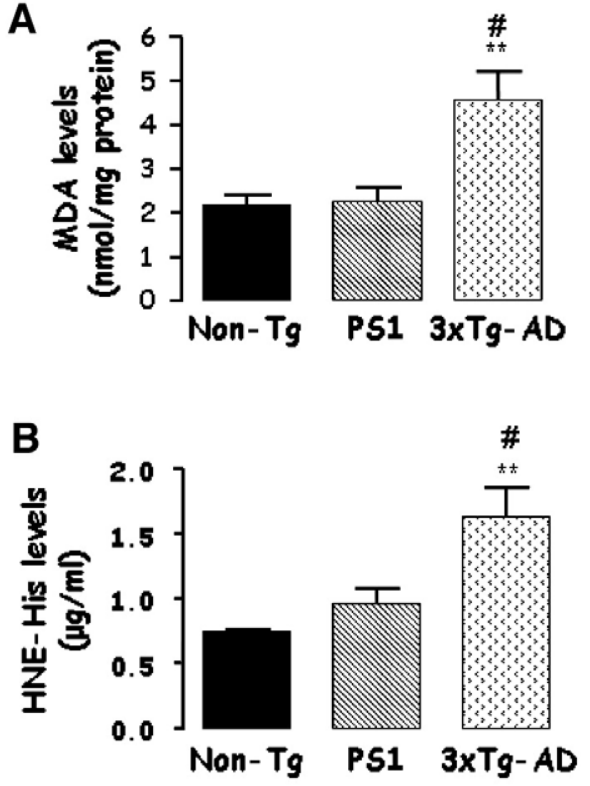

C

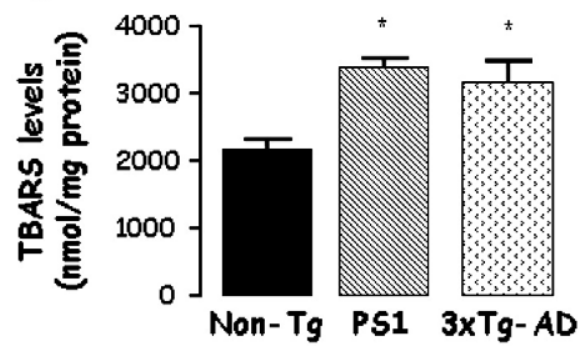

Fig. 1. Lipid peroxidation occurs in the brain of $3 \times \mathrm{Tg}-\mathrm{AD}$ mice. Brain homogenates were prepared from cerebral cortex of 3-to 5-month-old 3×Tg-AD mice and also age-matched PS1 and non-Tg mice and the extent of lipid peroxidation was evaluated by determining the production of (A) MDA, (B) HNE-His protein adduct, and (C) TBARS. Data, expressed as nanomoles per milligram of protein or microgram per milliliter, are means \pm SEM of the values from at least 10 animals. ${ }^{*} p<0.5$, ${ }^{* *} p<0.01$, statistically significant compared with the control mice. $\# p<0.5$, statistically significant compared with PS1 mice.

\section{Extraction and quantification of vitamin $E$}

Extraction and separation of vitamin $\mathrm{E}$ ( $\alpha$-tocopherol) from brain homogenates were performed by following a previously described protocol by Vatassery and Younoszai [33]. Briefly, $1.5 \mathrm{ml}$ sodium dodecyl sulfate ( $10 \mathrm{mM}$ ) was added to $0.5 \mathrm{mg}$ brain homogenate, followed by the addition of $2 \mathrm{ml}$ ethanol. Then, $2 \mathrm{ml}$ hexane and $50 \mu \mathrm{l}$ of $3 \mathrm{M} \mathrm{KCl}$ were added, and the mixture was vortexed for about $3 \mathrm{~min}$. The extract was centrifuged at $2000 \mathrm{rpm}$ (Sorvall RT6000 refrigerated centrifuge) and $1 \mathrm{ml}$ of the upper phase, containing $n$-hexane ( $n$-hexane layer), was recovered and evaporated to dryness under a stream of $\mathrm{N}_{2}$ and kept at $-80^{\circ} \mathrm{C}$. The extract was dissolved in $n$-hexane, and vitamin $\mathrm{E}$ content was analyzed by reverse-phase HPLC. A Spherisorb S10w column $(4.6 \times 200 \mathrm{~nm})$ was eluted with $n$-hexane modified with $0.9 \%$ methanol, at a flow rate of $1.5 \mathrm{ml} / \mathrm{min}$. Detection was performed by a UV detector at $287 \mathrm{~nm}$. The levels of vitamin E were calculated as nanomoles per milligram of protein.

\section{Statistical analysis}

Data were expressed as the means \pm SEM of the indicated number of experiments. Statistical significance was determined by using oneway ANOVA followed by Tukey post hoc tests. The differences were considered significant for $p$ values $<0.05$.

\section{Results}

Lipid peroxidation is enhanced in the $3 \times T g-A D$ mice

The extent of lipid peroxidation was evaluated by measuring the levels of MDA and TBARS, which are products of the oxidative modification of lipids [16,34]. HNE, another lipid peroxidation marker [16], structurally modifies proteins, forming stable adducts termed advanced lipid peroxidation end products. Because His residues are major targets [35], we have also quantified the levels of HNE-His protein adducts. Brain homogenates were prepared from the cerebral cortex of 3-to 5-month-old 3×Tg-AD mice and the levels of MDA, TBARS, and HNE-His were compared with those determined in agematched PS1 mice and also in non-Tg animals. At this age the $3 \times \mathrm{Tg}-\mathrm{AD}$ mouse has not yet developed neither amyloid plaques nor NFTs [19,20]. The PS1 mice express mutant PS1 protein at normal physiological levels in the absence of endogenous wild-type mouse PS1 [26]. As shown in Fig. $1 \mathrm{~A}$ an increase in MDA levels occurred in the brains of the $3 \times \mathrm{Tg}-\mathrm{AD}$ mice, but not in the PS1 mice. Similarly, the levels of HNE-His protein adduct are higher in $3 \times \mathrm{Tg}-\mathrm{AD}$ mice than in non- $\mathrm{Tg}$ and PS1 mice (Fig. 1B). A significant increase in the levels of TBARS was measured in both $3 \times \mathrm{Tg}-\mathrm{AD}$ and PS1 mice (Fig. 1C) compared with that determined in non-Tg littermates.

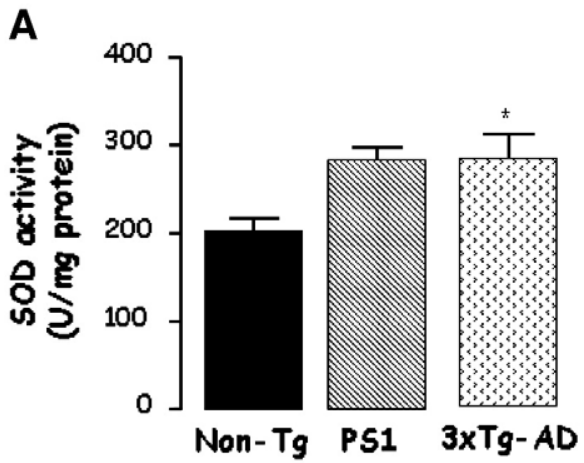

B

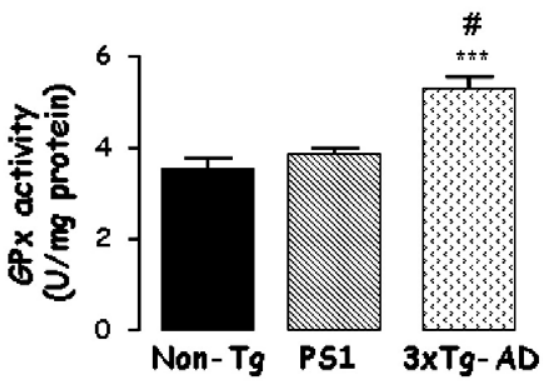

C

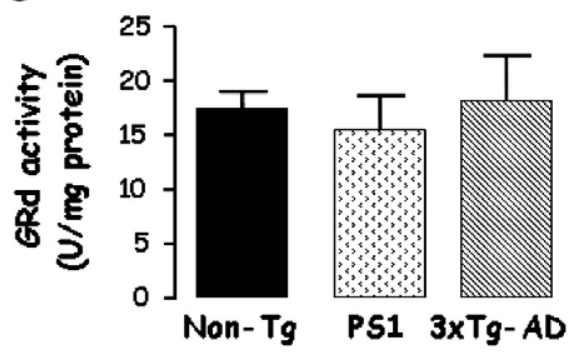

Fig. 2. The enzymatic activity of antioxidant enzymes is affected in the $3 \times \mathrm{Tg}-\mathrm{AD}$ mice. In brain homogenates prepared from 3-to 5-month-old 3×Tg-AD, PS1, and non-Tg mice the activity of (A) SOD and also of the enzymes of the glutathione redox cycle, (B) GPX and (C) GRd, was determined spectrophotometrically. Data, expressed as units per milligram of protein, are the means \pm SEM of the values from at least 10 animals. ${ }^{*} p<0.5$, $* * * p<0.001$, statistically significant compared with the control mice. $\# p<0.5$, statistically significant compared with PS1 mice. 
A

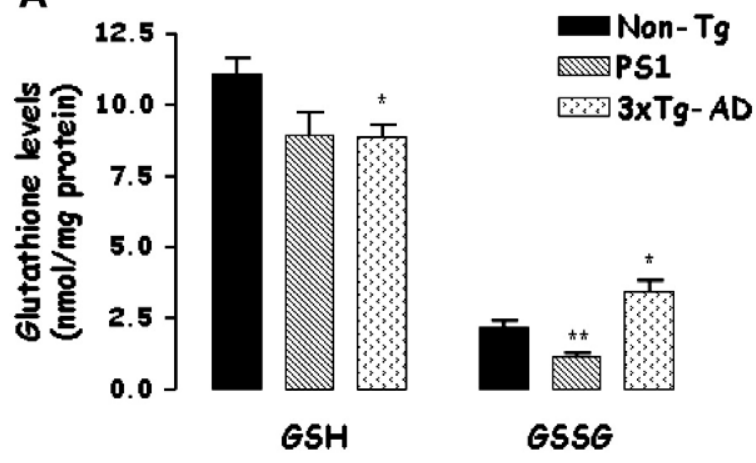

B

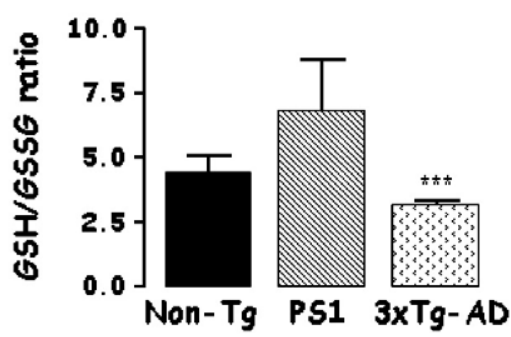

Fig. 3. GSH and GSSG levels and GSH/GSSG ratio are impaired in the $3 \times \mathrm{Tg}-\mathrm{AD}$ mice. Brain cortical homogenates were prepared from 3-to 5-month-old 3×Tg-AD, PS1, and non-Tg mice. (A) The levels of GSH and GSSG were determined using a fluorimetric assay and (B) GSH/GSSG ratio was calculated. Data, expressed as nanomoles per milligram of protein, are means \pm SEM of the values from at least 10 animals. ${ }^{*} p<0.5$, ${ }^{* *} p<0.01,{ }^{* * *} p<0.001$, statistically significant compared with the control mice.

The activity of antioxidant enzymes is increased in the brains of the $3 \times T g-A D$ mice

SOD, GPx, and GRd are three enzymes involved in cellular protection against damage induced by oxygen-derived free radicals [14]. The activity of these antioxidant enzymes was measured in brain homogenates prepared from the cerebral cortex of 3-to 5-month-old $3 \times \mathrm{Tg}-\mathrm{AD}$ mice, age-matched PS1, and wild-type littermates. Unlike the PS1 mice, a significant increase in the activities of SOD (Fig. 2A) and of GPx (Fig. 2B) was observed in the brains of the $3 \times \mathrm{Tg}-\mathrm{AD}$ animals compared with the controls. The activity of GRd, which is involved in GSH recycling, was not affected in the PS1 or $3 \times \mathrm{Tg}-\mathrm{AD}$ (Fig. 2C).

\section{Glutathione content is altered in $3 \times T g-A D$ mice}

GSH is one of the most relevant cellular nonenzymatic antioxidants [14]. In the $3 \times \mathrm{Tg}-\mathrm{AD}$ mice, GSH levels were significantly decreased with a concomitant increase of GSSG (Fig. 3A). As a consequence, the GSH/GSSG ratio determined in brain homogenates obtained from these mice was lower than that measured in the non- $\mathrm{Tg}$ littermates (Fig. 3B). On the other hand, in age-matched PS1 mice, the GSH levels were not significantly affected and GSSG deceased in a significant manner (Fig. 3A). As a result, GSH/GSSG ratio was not significantly changed in comparison with the non-Tg animals.

\section{Vitamin E levels are decreased in the $3 \times T g-A D$ mice}

Vitamin $\mathrm{E}$ is the most effective lipid-soluble antioxidant that is able to block the lipid peroxidation chain reaction [36]. As depicted in Fig. 4, the vitamin $\mathrm{E}$ content in $3 \times \mathrm{Tg}-\mathrm{AD}$ mice brain homogenates was significantly decreased compared with the control animals. In PS1 transgenic animals, the levels of this nonenzymatic antioxidant were not significantly different from those determined in the controls.

\section{Discussion}

Extracellular senile plaques mainly composed of fibrillar $A \beta[1]$ and NFTs composed of PHF of hyperphosphorylated tau [3] are the major neuropathological features of AD. Brain areas involved in learning and memory processes are reduced in size as a consequence of synaptic loss and neuronal death that seem to be associated with enhanced oxidative stress [4]. In fact, AD brains exhibit elevated levels of oxidative stress markers, namely protein carbonyls, TBARS, HNE, MDA, 8-OHdG, and 8 -OHG $[4,15,16,34]$. HNE readily reacts with proteins and HNEprotein adducts have been found in AD brains [37]. More recent studies of patients with amnestic mild cognitive impairment, the earliest manifestation of $\mathrm{AD}$, show similar patterns of oxidative damage [38]. These observations suggest that oxidative damage to critical biomolecules occurs early in the pathogenesis of $\mathrm{AD}$ and precedes pronounced neuropathologic alterations. Oxidative stress up-regulates BACE expression and activity [39] and increases $A \beta$ levels [13]. On the other hand, several in vitro [8-10] and in vivo [11] studies have demonstrated that oxidative stress is involved in $A \beta$-induced toxicity, which is prevented by antioxidants, namely vitamin $\mathrm{E}$ and melatonin.

In the present study we evaluated oxidative stress in a tripletransgenic model of AD ( $3 \times \mathrm{Tg}-\mathrm{AD})$. Epidemiologic studies have reported the higher incidence of AD in females [40-42], and Schuessel and colleagues [43] observed a gender-specific higher vulnerability in female AD patients toward oxidative stress. Taken together, these results led us to use female mice. The $3 \times \mathrm{Tg}-\mathrm{AD}$ mouse model develops senile plaques, NFTs, and cognitive impairments in an age-and regiondependent manner that closely mimics the human disease progression [19-21]. Intraneuronal $A \beta$ is first detected in cortical brain regions, whereas the most extensive tau immunoreactivity is apparent in the CA1 region of the hippocampus, progressively affecting neurons in the cerebral cortex of older animals. Despite equivalent overexpression of human APP and tau, $A \beta$ pathology precedes tau pathology by several months. Extracellular A $\beta$ deposits in cortex are apparent by 6 months of age but tau alterations are not apparent before 12 months of age [19]. In this work, we addressed the hypothesis that oxidative stress is an early event in the progression of $\mathrm{AD}$; therefore, we have used 3-to 5 -month-old animals that have not yet developed neither $A \beta$ nor tau pathologies. Even in the absence of these neuropathological hallmarks, an increase in the extent of lipid peroxidation, an oxidative stress marker, was observed. These results support other previous studies that demonstrate a negative correlation between oxidative damage and $\mathrm{A} \beta$ deposition in $\mathrm{AD}$ brain $[44,45]$ and support that oxidative stress is an early event in the development of $\mathrm{AD}[17,18]$. In the $3 \times \mathrm{Tg}-\mathrm{AD}$ mice, the oligomerization of $A \beta$ starts between 2 and 6 months of age [24], suggesting that the oxidative stress observed in the 3-to 5-month-old mice can be initiated by oligomeric $A \beta$. Recently, De Felice and colleagues [46] demonstrated that soluble forms of the $A \beta$ peptide, the amyloid-derived diffusible ligands, stimulate excessive formation of

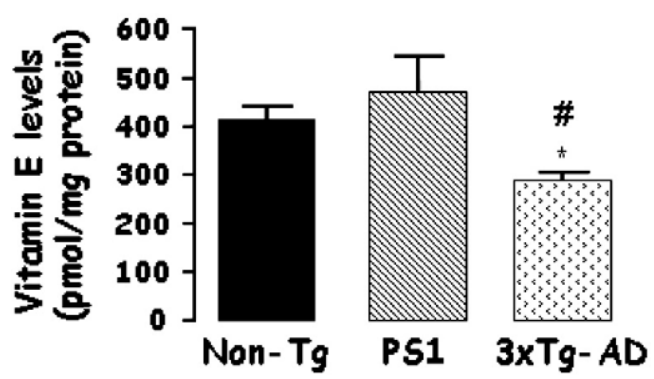

Fig. 4. The brain levels of the lipophilic antioxidant vitamin E are depleted in the $3 \times \mathrm{Tg}$ $\mathrm{AD}$ mice. Vitamin $\mathrm{E}$ ( $\alpha$-tocopherol) present in brain homogenates obtained from $3 \times \mathrm{Tg}$ AD, PS1, and non-Tg mice was measured by reverse-phase HPLC as described under Experimental procedures. ${ }^{*} p<0.5$, statistically significant compared with the control mice. Data, expressed as nanomoles per milligram of protein, are means \pm SEM of the values from at least 10 animals. \#p $<0.5$, statistically significant compared with PS1 mice. 


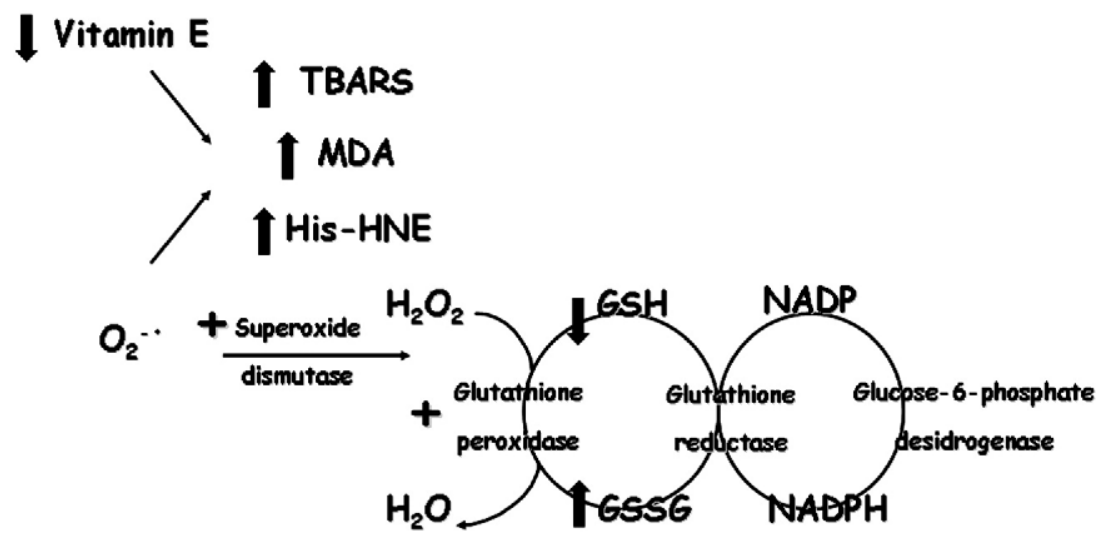

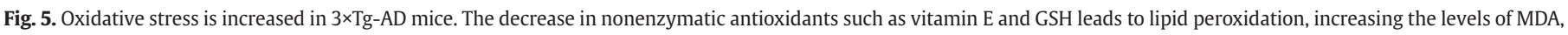

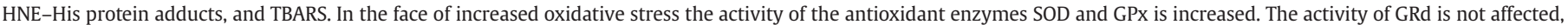
leading to a further depletion of GSH levels.

ROS through a mechanism requiring $N$-methyl-D-aspartate receptor activation. The higher neurotoxicity exerted by soluble $A \beta 1-42$ in comparison with fibrillar $A \beta$ suggests that this event can be mediated by an increase in oxidative stress leading to cell death [47]. The fibrillar form of the peptide, being less pro-oxidant and cytotoxic, may preferentially induce toxicity by modulating BACE- 1 expression and activity, increasing the amyloidogenic APP processing, and then resulting in a further accumulation of $A \beta$ [48]. Soluble $A \beta$ levels in Tg2576 mice have been directly correlated with increases in $\mathrm{H}_{2} \mathrm{O}_{2}$ [48], suggesting that soluble $A \beta$ may be responsible for its production.

Oxidative stress can be due to either an increase in ROS production or a decrease in the activity of the antioxidant enzymes such as SOD and GPx or nonenzymatic antioxidants, namely, vitamin E or GSH [14]. Manganese-SOD detoxifies superoxide anion $\left(\mathrm{O}_{2}{ }^{-}\right)$to give $\mathrm{H}_{2} \mathrm{O}_{2}$, which is then converted into $\mathrm{H}_{2} \mathrm{O}$ by either GPx or catalase [14]. We have observed that GPx activity is increased in $3 \times \mathrm{Tg}-\mathrm{AD}$ mice compared with the nontransgenic animals, which can be a protective mechanism to neutralize the formation of $\mathrm{H}_{2} \mathrm{O}_{2}$ produced by SOD, whose activity is also increased. Because the GRd activity is not statistically altered and GPx requires GSH as a substrate, the GSH levels are decreased and the GSSG levels are increased in 3×Tg-AD mice compared with controls. Similar results were obtained in cortical tissue from Tg2576 mice, in which the activities of SOD and GPx are increased [49]. The expression of SOD as well as of the GPX is higher in AD brains than in control non-AD brains [15,50].

Vitamin $\mathrm{E}$ and GSH, two nonenzymatic antioxidants, were shown to be decreased in the triple-transgenic model of AD and the levels of lipid peroxidation markers, namely MDA, HNE-His protein adduct, and TBARS, were increased. In another AD mouse model, the Tg2576 mice that carry the APP Swedish mutation, lipid peroxidation also precedes apparent $A \beta$ deposition and increases in $A \beta$ levels [18]. However, oxidative damage in these Tg mice that harbor APP or PS1 mutations appears later than in the $3 \times \mathrm{Tg}-\mathrm{AD}$ mice. Accordingly, in brain tissue from PS1 M146 L mice, increased levels of oxidative stress were observed only in aged animals (19-22 months of age) [51]. In this model, vitamin E reduces lipid peroxidation, and amyloid deposition [52] and a chronic antioxidant diet can reduce hippocampaldependent memory deficits without affecting $A \beta$ levels or plaque deposition [53]. Vitamin E-deficient rats, which undergo continuous oxidative stress, contain dystrophic neuritis analogous to that associated with the AD senile plaques [54]. PHF are more often found in neurites with membrane abnormalities indicative of lipid peroxidation, suggesting that oxidative stress may play a role in the development of neuritic abnormalities [55]. Because we have not observed alterations, neither in enzymatic nor in nonenzymatic antioxidants, in the PS1 knock-in mouse used in this work as a control, nor in the MDA or HNE-His levels, we can suggest that the presence of both APP and tau mutations can accelerate the appearance of oxidative stress markers. Although this hypothesis requires further investigation, it is supported by several findings. Increased tau pathology observed in aged homozygous transgenic mice harboring the P301L tau mutation was revealed in the altered lipid peroxidation levels and the up-regulation of antioxidant enzymes. Furthermore, these mice revealed an increased vulnerability of the mitochondria to $A \beta$ insult, suggesting a synergistic action of tau and $A \beta$ pathologies on mitochondrial function [56].

The early increase in oxidative stress can contribute to the development of NFTs in the $3 \times \mathrm{Tg}-\mathrm{AD}$ mice, detected at 12 months [20]. The involvement of oxidative stress and subsequent lipid peroxidation products in tau phosphorylation has been suggested [4]. Very recently, it has been demonstrated that mitochondrial oxidative stress causes hyperphosphorylation of tau in residues that are hyperphosphorylated in AD [57]. Lovell and colleagues [58] demonstrated a direct link between oxidative stress and tau phosphorylation in cortical neurons in culture. Moreover, modifications of tau by 4 -HNE promote and contribute to the generation of the major conformational properties defining neurofibrillary tangles occurring in AD brains [59].

In summary (Fig. 5), using a triple-transgenic mouse model that progressively develops amyloid plaques and tangles, we demonstrated that the decrease in nonenzymatic antioxidants such as vitamin $\mathrm{E}$ and GSH leads to lipid peroxidation, increasing the levels of MDA, HNE-His protein adducts, and TBARS. In addition, we observed an increase in the activity of the antioxidant enzymes SOD and GPX, providing evidence that neurons mobilize antioxidants in the face of increased oxidative stress. However, GRd was not affected and thus GSH levels are further depleted, contributing to oxidative damage to nucleic acids, proteins, and lipids. This study demonstrated that in $3 \times \mathrm{Tg}-\mathrm{AD}$ mice the oxidative stress occurs earlier than in other previously studied transgenic animals that carry only APP (Tg2576) $[18,49]$ or tau mutations (P301L) [56]. The obtained data support the amyloid cascade hypothesis [60], suggesting that oxidative stress is an early event in the development of AD and precedes the accumulation of $A \beta$ in senile plaques and the formation of NFTs. Altogether, this and other studies [61] suggest that antioxidant therapy may be beneficial if given at the early stages of the $\mathrm{AD}$ development.

\section{Acknowledgment}

Rosa Resende is a Ph.D. fellow from FCT (SFRH/BD/11005/2002).

\section{References}

[1] Terry, R. D.; Masliah, E.; Salmon, D. P.; Butters, N.; DeTeresa, R.; Hill, R.; Hansen, L. A.; Katzman, R. Physical basis of cognitive alterations in Alzheimer's disease: synaptic loss is the major correlate of cognitive impairment. Ann. Neurol. 30:572-580; 1991. 
[2] Price, D. L.; Sisodia, S. S.; Borchelt, D. R. Genetic neurodegenerative diseases: the human illness and transgenic models. Science 282:1079-1083; 1998.

[3] Avila, J. Tau protein, the main component of paired helical filaments. J. Alzheimers Dis. 9:171-175; 2006.

[4] Mattson, M. P. Pathways towards and away from Alzheimer's disease. Nature 430:631-639; 2004.

[5] Tanzi, R. E.; Kovacs, D. M.; Kim, T. W.; Moir, R. D.; Guenette, S. Y.; Wasco, W. The gene defects responsible for familial Alzheimer's disease. Neurobiol. Dis. 3:159-168; 1996.

[6] Butterfield, D. A.; Griffin, S.; Munch, G.; Pasinetti, G. M. Amyloid beta-peptide and amyloid pathology are central to the oxidative stress and inflammatory cascades under which Alzheimer's disease brain exists. J. Alzheimers Dis. 4:193-201; 2002.

[7] Haass, C.; Selkoe, D. J. Soluble protein oligomers in neurodegeneration: lessons from the Alzheimer's amyloid beta-peptide. Nat. Rev., Mol. Cell Biol. 8:101-112; 2007.

[8] Cardoso, S. M.; Oliveira, C. R. Glutathione cycle impairment mediates A betainduced cell toxicity. Free Radic. Res. 37:241-250; 2003.

[9] Melo, J. B.; Agostinho, P.; Oliveira, C. R. Involvement of oxidative stress in the enhancement of acetylcholinesterase activity induced by amyloid beta-peptide. Neurosci. Res. 45:117-127; 2003.

[10] Cutler, R. G.; Kelly, J.; Storie, K.; Pedersen, W. A.; Tammara, A.; Hatanpaa, K.; Troncoso, J. C.; Mattson, M. P. Involvement of oxidative stress-induced abnormalities in ceramide and cholesterol metabolism in brain aging and Alzheimer's disease. Proc. Natl. Acad. Sci. U. S. A. 101:2070-2075; 2004.

[11] Jhoo, J. H.; Kim, H. C.; Nabeshima, T.; Yamada, K.; Shin, E. J.; Jhoo, W. K.; Kim, W.; Kang, K. S.; Jo, S. A.; Woo, J. I. Beta-amyloid (1-42)-induced learning and memory deficits in mice: involvement of oxidative burdens in the hippocampus and cerebral cortex. Behav. Brain Res. 155:185-196; 2004.

[12] Paola, D.; Domenicotti, C.; Nitti, M.; Vitali, A.; Borghi, R.; Cottalasso, D.; Zaccheo, D.; Odetti, P.; Strocchi, P.; Marinari, U. M.; Tabaton, M.; Pronzato, M. A. Oxidative stress induces increase in intracellular amyloid $\beta$-protein production and selective activation of $\beta I$ and $\beta$ II PKCs in NT2 cells. Biochem. Biophys. Res. Commun. 268:642-646; 2000.

[13] Tamagno, E.; Parola, M.; Bardini, P.; Piccini, A.; Borghi, R.; Guglielmotto, M.; Santoro, G.; Davit, A.; Danni, O.; Smith, M. A.; Perry, G.; Tabaton, M. Beta-site APP cleaving enzyme up-regulation induced by 4-hydroxynonenal is mediated by stress-activated protein kinases pathways. J. Neurochem. 92:628-636; 2005

[14] Chauhan, V.; Chauhan, A. Oxidative stress in Alzheimer's disease. Pathophysiology 13:195-208; 2006.

[15] Lovell, M. A.; Ehmann, W. D.; Butler, S. M.; Markesbery, W. R. Elevated thiobarbituric acid-reactive substances and antioxidant enzyme activity in the brain in Alzheimer's disease. Neurology 45:1594-1601; 1995

[16] Butterfield, D. A.; Reed, T.; Newman, S. F.; Sultana, R. Roles of amyloid $\beta$-peptideassociated oxidative stress and brain protein modifications in the pathogenesis of Alzheimer's disease and mild cognitive impairment. Free Radic. Biol. Med. 43:658-677; 2007.

[17] Nunomura, A.; Perry, G.; Aliev, G.; Hirai, K.; Takeda, A.; Balraj, E. K.; Jones, P. K.; Ghanbari, H.; Wataya, T.; Shimohama, S.; Chiba, S.; Atwood, C. S.; Petersen, R. B.; Smith, M. A. Oxidative damage is the earliest event in Alzheimer disease. J. Neuropathol. Exp. Neurol. 60:759-767; 2001.

[18] Praticò, D.; Uryu, K.; Leight, S.; Trojanoswki, J. Q.; Lee, V. M. Increased lipid peroxidation precedes amyloid plaque formation in an animal model of Alzheimer amyloidosis. J. Neurosci. 21:4183-4187; 2001.

[19] Oddo, S.; Caccamo, A.; Shepherd, J. D.; Murphy, M. P.; Golde, T. E.; Kayed, R.; Metherate, R.; Mattson, M. P.; Akbari, Y.; LaFerla, F. M. Triple-transgenic model of Alzheimer's disease with plaques and tangles: intracellular $\mathrm{Ab}$ and synaptic dysfunction. Neuron 39:409-421; 2003.

[20] Oddo, S.; Caccamo, A.; Kitazawa, M.; Tseng, B. P.; LaFerla, F. M. Amyloid deposition precedes tangle formation in a triple transgenic model of Alzheimer's disease. Neurobiol. Aging 24:1063-1070; 2003.

[21] Billings, L. M.; Oddo, S.; Green, K. N.; McGaugh, J. L.; LaFerla, F. M. Intraneuronal Abeta causes the onset of early Alzheimer's disease-related cognitive deficits in transgenic mice. Neuron 45:675-688; 2005.

[22] Oddo, S.; Caccamo, A.; Cheng, D.; Jouleh, B.; Torp, R.; LaFerla, F. M. Genetically augmenting tau levels does not modulate the onset or progression of Abeta pathology in transgenic mice. J. Neurochem. 102:1053-1063; 2007.

[23] Oddo, S.; Billings, L.; Kesslak, J. P.; Cribbs, D. H.; LaFerla, F. M. Abeta immunotherapy leads to clearance of early, but not late, hyperphosphorylated tau aggregates via the proteasome. Neuron 43:321-332; 2004.

[24] Oddo, S.; Caccamo, A.; Tran, L.; Lambert, M. P.; Glabe, C. G.; Klein, W. L.; LaFerla, F. M. Temporal profile of amyloid-beta (Abeta) oligomerization in an in vivo model of Alzheimer disease: a link between Abeta and tau pathology. J. Biol. Chem. 28:1599-15604; 2006

[25] Billings, L. M.; Green, K. N.; McGaugh, J. L.; LaFerla, F. M. Learning decreases A beta*56 and tau pathology and ameliorates behavioral decline in $3 \times \mathrm{Tg}-\mathrm{AD}$ mice. J. Neurosci 27:751-761; 2007.

[26] Guo, Q.; Fu, W.; Sopher, B. L.; Miller, M. W.; Ware, C. B.; Martin, G. M.; Mattson, M. P. Increased vulnerability of hippocampal neurons to excitotoxic necrosis in presenilin-1 mutant knock-in mice. Nat. Med. 5:101-106; 1999.

[27] Buege, J. A.; Aust, S. D. Microsomal lipid peroxidation. In: Colowick, S.P., Kaplan, N. O. (Eds.), Methods in Enzymology, vol. 52. Academic Press, New York,pp. 302-310. pp.; 1967.

[28] Wong, S. H.; Knight, J. A.; Hopfer, S. M.; Zaharia, O.; Leach Jr., C. N.; Sunderman Jr., F. W. Lipoperoxides in plasma as measured by liquid-chromatographic separation of malondialdehyde-thiobarbituric acid adduct. Clin. Chem. 33:214-220; 1987.
[29] Flohe, L.; Otting, F. Superoxide dismutase assays. Methods Enzymol. 105:93-104; 1984.

[30] Paglia, D. E.; Valentine, W. N. Studies on the quantitative and qualitative characterization of erythrocyte glutathione peroxidase. J. Lab. Clin. Med. 70:158-169; 1967.

[31] Goldberg, D. M.; Richard, S. J. Methods enzymatic analysis. Academic Press, New York,pp. 258-265; 1983.

[32] Hissin, P. J.; Hilf, R. A fluorometric method for determination of oxidized and reduced glutathione in tissues. Anal. Biochem. 74:214-226; 1976.

[33] Vatassery, G. T.; Younoszai, R. Alpha tocopherol levels in various regions of the central nervous systems of the rat and guinea pig. Lipids 13:828-831; 1978.

[34] Petersen, R. B.; Nunomura, A.; Lee, H. G.; Casadesus, G.; Perry, G.; Smith, M. A.; Zhu, X. Signal transduction cascades associated with oxidative stress in Alzheimer's disease. J. Alzheimers Dis. 1:143-152; 2007.

[35] Uchida, K.; Stadtman, E. R. Modification of histidine residues in proteins by reaction with 4-hydroxynonenal. Proc. Natl. Acad. Sci. U. S. A. 89:4544-4548; 1992

[36] Machlin, L. J.; Bendich, A. Free radical tissue damage: protective role of antioxidant nutrients. FASEB J. 1:441-445; 1987.

[37] Sayre, L. M.; Zelasko, D. A.; Harris, P. L.; Perry, G.; Salomon, R. G.; Smith, M. A. 4Hydroxynonenal-derived advanced lipid peroxidation end products are increased in Alzheimer's disease. J. Neurochem. 68:2092-2097; 1997.

[38] Lovell, M. A.; Markesbery, W. R. Oxidative DNA damage in mild cognitive impairment and late-stage Alzheimer's disease. Nucleic Acids Res. 35:7:497-7504; 2007.

[39] Tamagno, E.; Bardini, P.; Obbili, A.; Vitali, A.; Borghi, R.; Zaccheo, D.; Pronzato, M. A.; Danni, O.; Smith, M. A.; Perry, G.; Tabaton, M. Oxidative stress increases expression and activity of BACE in NT2 neurons. Neurobiol. Dis. 10:279-288; 2002.

[40] Andersen, K.; Launer, L. J.; Dewey, M. E.; Letenneur, L.; Ott, A.; Copeland, J. R.; Dartigues, J. F.; Kragh-Sorensen, P.; Baldereschi, M.; Brayne, C.; Lobo, A.; MartinezLage, J. M.; Stijnen, T.; Hofman, A. Gender differences in the incidence of AD and vascular dementia: the EURODEM studies. EURODEM Incidence Research Group. Neurology 53:1992-1997; 1999.

[41] Brayne, C.; Gill, C.; Huppert, F. A.; Barkley, C.; Gehlhaar, E.; Girling, D. M.; O'Connor, D. W.; Paykel, E. S. Incidence of clinically diagnosed subtypes of dementia in an elderly population. Cambridge Project for Later Life. Br. J. Psychiatry 167:255-262; 1995.

[42] Fratiglioni, L.; Viitanen, M.; von Strauss, E.; Tontodonati, V.; Herlitz, A.; Winblad, B. Very old women at highest risk of dementia and Alzheimer's disease: incidence data from the Kungsholmen Project, Stockholm. Neurology 48:132-138; 1997.

[43] Schuessel, K.; Leutner, S.; Cairns, N. J.; Müller, W. E.; Eckert, A. Impact of gender on upregulation of antioxidant defence mechanisms in Alzheimer's disease brain. J. Neural Transm. 111:1167-1182; 2004.

[44] Mclean, C. A.; Cherny, R. A.; Fraser, F. W.; Fuller, S. J.; Smith, M. J.; Beyreuther, K.; Bush, A. I.; Masters, C. L. Soluble pool of Ab amyloid as a determinant of severity of neurodegeneration in Alzheimer's disease. Ann. Neurol. 46:860-866; 1999.

[45] Wang, J.; Dickson, D. W.; Trojanowski, J. Q.; Lee, V. M. The levels of soluble versus insoluble brain $A B$ distinguish Alzheimer's disease from normal and pathologic aging. Exp. Neurol. 158:328-337; 1999.

[46] De Felice, F. G.; Velasco, P. T.; Lambert, M. P.; Viola, K.; Fernandez, S. J.; Ferreira S. T.; Klein, W. L. Abeta oligomers induce neuronal oxidative stress through an $\mathrm{N}$-methyl-D-aspartate receptor-dependent mechanism that is blocked by the Alzheimer drug memantine. J. Biol. Chem. 282:11590-11601; 2007.

[47] Tamagno, E.; Bardini, P.; Guglielmotto, M.; Danni, O.; Tabaton, M. The various aggregation states of $\beta$-amyloid 1-42 mediate different effects on oxidative stress, neurodegeneration, and BACE-1 expression. Free Radic. Biol. Med. 41:202-212; 2006.

[48] Manczak, M.; Anekonda, T. S.; Henson, E.; Park, B. S.; Quinn, J.; Reddy, P. H. Mitochondria are a direct site of A beta accumulation in Alzheimer's disease neurons: implications for free radical generation and oxidative damage in disease progression. Hum. Mol. Genet. 15:1437-1449; 2006.

[49] Apelt, J.; Bigl, M.; Wunderlich, P.; Schliebs, R. Aging-related increase in oxidative stress correlates with developmental pattern of beta-secretase activity and betaamyloid plaque formation in transgenic Tg2576 mice with Alzheimer-like pathology. Int. J. Dev. Neurosci. 22:475-484; 2004.

[50] De Leo, M. E.; Borrello, S.; Passantino, M.; Palazzotti, B.; Mordente, A.; Daniele, A.; Filippini, V.; Galeotti, T.; Masullo, C. Oxidative stress and overexpression of manganese superoxide dismutase in patients with Alzheimer's disease. Neurosci Lett. 250:173-176; 1998.

[51] Schuessel, K.; Frey, C.; Jourdan, C.; Keil, U.; Weber, C. C.; Müller-Spahn, F.; Müller W. E.; Eckert, A. Aging sensitizes toward ROS formation and lipid peroxidation in PS1M146L transgenic mice. Free Radic. Biol. Med. 40:850-862; 2006.

[52] Sung, S.; Yao, Y.; Uryu, K.; Yang, H.; Lee, V. M.; Trojanowski, J. Q.; Praticò, D. Early vitamin E supplementation in young but not aged mice reduces Abeta levels and amyloid deposition in a transgenic model of Alzheimer's disease. FASEB J. 18:323-325; 2004.

[53] Quinn, J. F.; Bussiere, J. R.; Hammond, R. S.; Montine, T. J.; Henson, E.; Jones, R. E.; Stackman Jr., R. W. Chronic dietary alpha-lipoic acid reduces deficits in hippocampal memory of aged Tg2576 mice. Neurobiol. Aging 28:213-225; 2007.

[54] Heslop, K. E.; Goss-Sampson, M. A.; Muller, D. P.; Curzon, G. Serotonin metabolism and release in frontal cortex of rats on a vitamin E-deficient diet. J. Neurochem 66:860-864; 1996

[55] Praprotnik, D.; Smith, M. A.; Richey, P. L.; Vinters, H. V.; Perry, G. Plasma membrane fragility in dystrophic neurites in senile plaques of Alzheimer's disease: an index of oxidative stress. Acta Neuropathol. 91:1-5; 1996.

[56] David, D. C.; Hauptmann, S.; Scherping, I.; Schuessel, K.; Keil, U.; Rizzu, P.; Ravid, R Dröse, S.; Brandt, U.; Müller, W. E.; Eckert, A.; Götz, J. Proteomic and functional 
analyses reveal a mitochondrial dysfunction in P301L tau transgenic mice. J. Biol. Chem. 280:23802-23814; 2005.

[57] Melov, S.; Adlard, P. A.; Morten, K.; Johnson, F.; Golden, T. R.; Hinerfeld, D.; Schilling, B.; Mavros, C.; Masters, C. L.; Volitakis, I.; Li, Q. X.; Laughton, K.; Hubbard, A.; Cherny, R. A.; Gibson, B.; Bush, A. I. Mitochondrial oxidative stress causes hyperphosphorylation of tau. PLoS ONE 2:e536; 2007.

[58] Lovell, M. A.; Xiong, S.; Xie, C.; Davies, P.; Markesbery, W. R. Induction of hyperphosphorylated tau in primary rat cortical neuron cultures mediated by oxidative stress and glycogen synthase kinase-3. J. Alzheimers Dis. 6:659-671; 2004.
[59] Liu, Q.; Smith, M. A.; Avilá, J.; DeBernardis, J.; Kansal, M.; Takeda, A.; Zhu, X.; Nunomura, A.; Honda, K.; Moreira, P. I.; Oliveira, C. R.; Santos, M. S.; Shimohama, S.; Aliev, G.; de la Torre, J.; Ghanbari, H. A.; Siedlak, S. L.; Harris, P. L.; Sayre, L. M.; Perry, G. Alzheimer-specific epitopes of tau represent lipid peroxidation-induced conformations. Free Radic. Biol. Med. 38:746-754; 2005.

[60] Hardy, J.; Selkoe, D. J. The amyloid hypothesis of Alzheimer's disease: progress and problems on the road to therapeutics. Science 297:353-356; 2002.

[61] Smith, D. G.; Cappai, R.; Barnham, K. J. The redox chemistry of the Alzheimer's disease amyloid beta peptide. Biochim. Biophys. Acta 1768:1976-1990; 2007. 